\title{
Estudos da Interpretação: quem tem medo das línguas de sinais?
}

\author{
Maria Cristina Pires Pereira*
}

\section{Introdução ${ }^{1}$}

Os Estudos da Interpretação podem ser considerados como um desdobramento recente ou subárea dos Estudos da Tradução e, como tal, ainda apresentam lacunas em seu arcabouço teórico, descritivo e tipológico. Uma destas áreas, carentes de maior conexões de afiliação, é a que abrange a interpretação de línguas de sinais. Considerada, em alguns momentos, como um mero instrumento de acessibilidade, muitas vezes o seu aspecto de mediação bilíngue escapa até mesmo a pesquisadores que lidam com a Interpretação somente de línguas orais.

Se analisarmos que a interpretação interlíngue surgiu em tempos remotos, sem tecnologias que possibilitassem outras formas de mediação entre línguas que não fosse a presencial, na qual os interlocutores estivessem face a face e em um espaço físico que permitisse uma interação síncrona entre eles, não é de estranhar que houvesse somente a concepção

\footnotetext{
* Maria Cristina Pires Pereira é doutora em Estudos da Tradução (UFSC), mestre em Linguística Aplicada (Unisinos) e docente do curso de bacharelado em Letras - Tradutor e Intérprete de Português e Libras da Universidade Federal do Rio Grande do Sul.

${ }^{1}$ Meus agradecimentos a Heidemarie Salevsky por sua colaboração acadêmica ao disponibilizar artigo necessário para a composição deste texto e a Ricardo Rodriguez Palácios pela revisão do abstract.
} 
de interpretação de e para uma língua falada oralmente (vocalmente), e tradução de e para uma língua escrita. Com a evolução dos meios de comunicação e da tecnologia, as modalidades híbridas entre traduções escritas e interpretações faladas compõem um desafio terminológico e conceitual ainda não resolvido de uma forma satisfatória e consensual.

Alguns autores ainda definem a interpretação interlíngue em termos de oralidade (Pearl, 2007), chegando a denominá-la de "tradução oral" (Ivars, 1999), deixando, com isso, a interpretação de línguas de sinais excluída. Esta desconsideração das línguas de sinais subestima o seu estatuto linguístico e talvez, infelizmente, assuma uma visão das pessoas surdas como usuárias de um código comunicativo na forma de mímica, pantomima, ou de uma corruptela da língua oral, e não como falantes de uma língua plena, porém de modalidade diferente.

Embora Carneiro (2017, p.2) argumente que "os intérpretes de Libras [acrônimo de Língua Brasileira de Sinais] no Brasil ainda não se veem como pertencentes ao grupo seleto e socialmente prestigiado dos intérpretes de línguas orais", defendo uma perspectiva diferente: os intérpretes de línguas de sinais não são, ainda, plenamente aceitos como parte da categoria dos intérpretes. $\mathrm{O}$ desconhecimento de que a interpretação de línguas de sinais é interpretação interlíngue, como ocorre entre quaisquer outras línguas, causa equívocos e classificações mal feitas como exponho nos dois casos a seguir:

No Código Brasileiro de Ocupações (CBO), publicado pelo Ministério do Trabalho e Emprego, existe a denominada família dos filólogos, tradutores, intérpretes e afins sob o código 2614, e a subdivisão 2614-10 designava todos os intérpretes, intérpretes comerciais, intérpretes de comunicação eletrônica, intérpretes de conferência, intérpretes simultâneos, tradutores simultâneos. No entanto, a partir de 2010, foi criada uma nova subdivisão com o código 2614-25 para os intérpretes de língua de sinais, guias-intérpretes, intérpretes de Libras, intérpretes educacionais, tradutores de Libras, tradutores-intérpretes de Libras. Analisemos a situação, hipotética, mas perfeitamente factível, de um intérprete de língua de sinais, contratado para interpretar conferências: em qual CBO será seu registro? Outro caso possível seria de um intérprete de 
crioulo haitiano que fosse requisitado a interpretar para alunos filhos de imigrantes, até que estes adquirissem uma boa proficiência em português para acompanhar as aulas: seria ele registrado como CBO 2614-25, de intérprete educacional (mas que se encontra circunscrito ao grupo das línguas de sinais)? O CBO adotou uma classificação muito problemática, portanto.

Maya de Wit tornou-se, somente em 2014, a primeira intérprete de uma língua de sinais admitida pela Associação Internacional de Intérpretes de Conferência (AIIC) (Monfort, 2014), embora existam registros da atuação de intérpretes de línguas de sinais, em conferências, há décadas (Brunson, 2004).

Ocorrem vários outros casos, a maioria ainda não documentados e que circulam informalmente entre nós, intérpretes de línguas de sinais, nos quais existem evidências de que somos considerados um grupo à parte, "especiais", talvez com um viés até caritativo e somente voltado para a acessibilidade, sem considerar os aspectos culturais e linguísticos envolvidos.

O que não deveria acontecer é que a temática da interpretação de línguas de sinais fosse evitada por puro desconhecimento, ou receio, e trago dois exemplos pessoais. O primeiro aconteceu em minha tentativa de submeter um artigo, em 2009, ao Translation Journal, do qual obtive a seguinte resposta do editor:

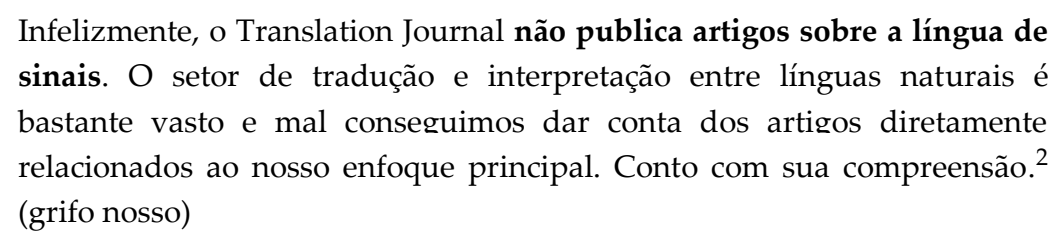

Não me foi fornecida nenhuma justificativa adicional ou argumentação consistente para a exclusão da interpretação de línguas de sinais de um periódico sobre tradução.

\footnotetext{
${ }^{2}$ Comunicação pessoal. BOKOR, Gabe. The form from Translation Journal does not work [mensagem pessoal]. Mensagem recebida e autorizada por gbokor@translationjournal.net, em 17 out. 2013.
} 
O segundo exemplo é o da disciplina Tópicos em Estudos da Interpretação, oferecida pelo Programa de Doutorado e Mestrado em Estudos da Tradução (TRADUSP), da Faculdade de Filosofia, Letras e Ciências Humanas (FFLCH), da Universidade de São Paulo (USP), em que existe a seguinte ressalva:

\begin{abstract}
A disciplina proposta não visa a tratar de questões da interpretação de língua de sinais, mas somente da interpretação enquanto intermediação entre diferentes línguas orais. Embora haja algumas questões teóricas próximas no estudo da interpretação de línguas orais e de línguas de sinais, o estudo dessa segunda modalidade exigiria bibliografia e métodos especializados, que fogem ao escopo da disciplina ora proposta. ${ }^{3}$ (grifo nosso)
\end{abstract}

O aspecto conflitante é que, no mesmo link, na descrição do conteúdo da disciplina, não consta nada que não pudesse ser abordado na interpretação de línguas de sinais:

1. Panorama histórico da profissão de intérprete no mundo e no Brasil. 2. Panorama histórico da pesquisa acadêmica na área dos Estudos da Interpretação. 3. Visão geral dos principais modelos teóricos utilizados na formação de intérpretes e nos Estudos da Interpretação em geral. 4. Normas fundamentais de pesquisa. 5. Metodologias de pesquisa. 6. Leitura crítica de textos acadêmicos. 7. Seleção de tópicos e planejamento de projetos de pesquisa. 8. A teorização da interpretação: memes e modelos. 9. Pesquisa em interpretação: foco em qualidade. 10. A Teoria Interpretativa da Tradução (Théorie du Sens). 11. O Modelo dos Esforços ("Effort Models"). 12. As formas distintas de interpretação: simultânea, consecutiva, comunitária e judicial.

Obviamente que o objetivo da disciplina poderia não ser $o$ oferecimento em tópico separado, ou inserido em cada um deles, de uma parte reservada para o estudo da interpretação de línguas de sinais, mas não há motivo, em termos acadêmicos, para que haja esta separação, pois 
os aspectos em comum são mais presentes do que os aspectos diferenciadores. Se a meta não é o aprofundamento na interpretação de línguas de sinais, o assunto “ 1 . Panorama histórico da profissão de intérprete no mundo e no Brasil" já seria suficiente para mencionar a existência de profissionais que se dedicam a interpretar de e para línguas na modalidade sinalizada. Em uma disciplina geral, que pretendesse dar uma visão abrangente, um texto que apresentasse a interpretação de línguas de sinais como parte dos Estudos da Interpretação já seria suficientemente informativo para quem estudasse esta disciplina. A interpretação de línguas de sinais, apesar de suas especificidades, não é algo tão exótico que justifique uma nota avisando sobre "bibliografia e métodos especializados" que, convenhamos, também são necessários para estudar a interpretação jurídica ou médica, por exemplo.

Internacionalmente existem amostras desta falta de coesão terminológica e tipológica. Apenas citando dois casos recentes, o primeiro da fanpage do Facebook, da Associação Internacional de Intérpretes de Conferência (AIIC), chamada Interpreting the World. No dia 3 de maio de 2017, foi postada a seguinte mensagem:

\begin{tabular}{l} 
Interpreting the World \\
What must be made absolutely clear is that: \\
1) translators who work with written texts are not interpreters who work \\
orally; \\
2) a translator or interpreter does not perform any investigative \\
functions, it is not their job but that of a bilingual investigator. It is a \\
different profession. \\
3) and, that professional interpreters and translators abide by the \\
strictest codes of ethics, and are impartial and neutral. \\
Ver Tradução \\
(1) Você e outras 10 pessoas \\
\hline Curtir
\end{tabular}




\section{Figura 1 - Imagem da fanpage da Interpreting the World}

Fonte: Disponível em:

https://www.facebook.com/aiic.interpreters/posts/1496207247118155.

Pode-se perceber que até mesmo uma associação internacional que trabalha com interpretação ainda não tem uma consciência clara de que interpretação de línguas de sinais também é interpretação. Após um comentário apontando o equívoco, a postagem foi corrigida para "1) translators who work with written texts are not interpreters who work with spoken or sign language". ${ }^{4}$

O outro caso, que consta na figura 2, é a apresentação do evento Translation [and Interpreting] in Transition 3, ocorrido em 13 e 14 de julho de 2017, na Universidade de Ghent, na Bélgica, em que a interpretação de línguas de sinais é classificada como uma forma híbrida de tradução. A conferência apresenta-se com um fórum para pesquisadores envolvidos em: "[...] interpretação, e formas híbridas (tradução audiovisual, legendagem ao vivo [closed caption], tradução à vista e interpretação de língua de sinais..." (tradução nossa).

\footnotetext{
${ }^{4}$ Disponível em: https://www.facebook.com/aiic.interpreters/posts/1496207247118155.
} 
$\widehat{\widehat{\text { IIIIIII }}}$

\section{GHENT UNIVERSITY}

Important dates:

10.112016

First CFP

07.02:2017:

Deadline for submissions

01.04:2017:

Registration opens

13-14.07.2017:

After successful editions in Copenhagen in 2014 and Germersheim in 2015, we are pleased to announce that the third Translation in Transition Conference will be held on July 13-14, 2017 at the department of Translation, Interpreting and Communication of Ghent University (Belgium).

TT3 wants to offer a forum to researchers involved with the theory-informed empirical study of translation, interpreting and hybrid forms (audio-visual translation, live-subtitling, sight translation, sign language interpreting....). We are particularly interested to hear how methods and technologies that are typically associated with product research (corpus-based methods, statistical data analysis) or process research (EEG, keystroke logging, eye-tracking) can be successfully combined in both translation and interpreting research

Read more

symposium

Sponsors:

\section{fwo}

Figura 2 - Imagem da divulgação do evento Translation [and Interpreting] in Transition 2017

Fonte: Imagem retirada da Internet, disponível em

< $\underline{\text { http://www.eqtis.ugent.be/tt3/index.htm> }}$, acesso em: 14 ago. 2017

Considerando este panorama, é necessária uma revisão, sistematização e atualização do que é considerado como interpretação de línguas de sinais e sua classificação, dentro dos Estudos da Interpretação para, até mesmo, colocar novamente em discussão nossas visões sobre quais os impactos que o reconhecimento desta forma de interpretação tem causado na sociedade e na área acadêmica.

\section{Motivos para não Descartar as Línguas de Sinais}

As línguas de sinais nascem e, inicialmente, são cultivadas nas comunidades surdas e, nos dias de hoje, transitam em diversos espaços não 
só acadêmicos, mas também comunitários e culturais e devem ser consideradas como "um sistema linguístico legítimo e não como um problema do surdo ou como uma patologia da linguagem" (Quadros; Karnopp, 2004, p. 30), pois

\begin{abstract}
São incontáveis os estudos que, a partir das observações pioneiras de William Stokoe (1960), e, a seguir, de Klima e Bellugi (1979), têm demonstrado que as línguas de sinais são duplamente articuladas, exibindo rica fonologia e uma morfologia que segue alguns dos padrões de composição das línguas orais; que elas constroem significação tão amplamente quanto qualquer outra língua natural; e, de um ponto de vista discursivo, que elas são eficientes meios de comunicação, adquiridos espontaneamente por crianças a eles expostas, e amplamente utilizados pelas diversas comunidades surdas em todo o mundo, para a expressão de ideias, sentimentos, e pontos de vista, em diferentes estilos e registros (Mccleary; Viotti, 2011, p.289).
\end{abstract}

Segundo a Federação Mundial de Surdos (FMS), "existem 70 milhões de pessoas surdas que utilizam a língua de sinais como sua primeira língua ou língua materna" e a única universidade no mundo na qual as aulas são ministradas em Língua Americana de Sinais, ou Língua Estadunidense de Sinais (American Sign Language - ASL), a Gallaudet University, em Washington D.C., cataloga 271 línguas de sinais, dialetos e outros sistemas sinalizados no mundo. ${ }^{5}$

O primeiro texto a circular no Brasil sobre a língua de sinais brasileira foi “Fundamentos Linguísticos para a Descrição da Linguagem de Sinais do Brasil" (Rehfeldt, 1983) que, curiosamente, foi uma tradução de um capítulo de um livro originalmente publicado nos Estados Unidos (Hoemann; Oates; Hoemann, 1981).

Inicialmente designada como Língua de Sinais dos Centros Urbanos Brasileiros (LSCB) (Ferreira, 2010), a mais divulgada e utilizada língua de sinais no Brasil é atualmente conhecida por Libras (acrônimo de Língua Brasileira de Sinais). Também mencionada pela sigla LSB (Língua de Sinais

\footnotetext{
${ }^{5}$ Gallaudet University Library. Disponível em: http://libguides.gallaudet.edu/content.php?pid=114804\&sid=991940. Acessado em 22 out.2017.
} 
Brasileira), possui outras identificações menos utilizadas como $\mathrm{BZS}^{6}$ e sgnBR (Everson, 2000). Foi reconhecida, em âmbito federal, como "meio legal de comunicação e expressão" pela Lei № 10.436, de 24 de abril de 2002.

Além da Libras, coexistem, nacionalmente, diversas línguas de sinais emergentes (Meir et Al., 2010):

- Indígenas: Língua de Sinais [Urubu] Kaapor ou Língua de Sinais Ka'apor (Kakumasu, 1968, 1986; Ferreira, 2010), Sinais Kaingang da Aldeia - SKA (Giroletti, 2008), Sinais Terena (Sumaio, 2014);

- De pequenas comunidades (Village Sign Language, De Vos; Zeshan, 2012): Língua de Sinais Cena (Pereira, 2013) e a Língua de Sinais Marajó (Martinod, 2013; Carliez; Fusellier, 2016);

- Fronteiriças: Libralsu, da fronteira Brasil e Uruguai (Figueira, 2016).

- Possivelmente, na recente onda migratória de venezuelanos, haitianos, senegaleses etc. para o Brasil, também deve haver pessoas surdas com suas línguas de sinais de imigração. Mesmo em contexto europeu, “a imigração de pessoas surdas para países estrangeiros é um tema que não tem sido estudado em detalhes" (Savulahti, 2012, p.8) e quase nada foi feito a respeito da interpretação destas línguas.

E, devo registrar, existe também um outro tipo de língua de sinais, além daquelas que são percebidas de forma visual: são as línguas de sinais táteis, utilizadas pelas pessoas surdocegas, que ainda carecem de estudos em relação a sua categorização na área dos Estudos da Interpretação (Lourenço, 2012; Petronio, 2010).

Provavelmente, devem existir mais línguas de sinais, no Brasil e no mundo, que, não foram registradas, nem descritas e que, a partir de sua

\footnotetext{
${ }^{6}$ SIL International. ISO 639 family of standards, Codes for the representation of names of languages. Disponível em: http://www-01.sil.org/iso639-3/default.asp. Acessado em: 20 out. 2017.
} 
análise, fornecerão mais subsídios para a ampliação de nossa concepção sobre as possibilidades da linguagem humana.

Como argumento, a razão mais saliente para não descartarmos as línguas de sinais é que elas fazem parte do grande repertório linguístico possível aos seres humanos embora, infelizmente, ainda enfrentem o desconhecimento da maioria da população. Ainda existem aspectos que precisam ser investigados para serem inseridos nos meios acadêmicos e, entre estes fenômenos, só muito recentemente as línguas de sinais passaram a ser incluídas como merecedoras de pesquisas. No entanto, a interpretação interlíngue na qual, pelo menos, uma das línguas é sinalizada ainda vem sendo definida e categorizada de uma forma pouco precisa e até marginal dentro dos Estudos da Interpretação.

\section{Por que a Interpretação de Línguas de Sinais Conta?}

Se considerarmos que "a interpretação de línguas de sinais é uma parte integrante do estudo geral da interpretação e nenhuma descrição (prática ou teórica) da interpretação que não a tiver em conta pode ser considerada como completa" (Ingram 1978, apud Bidoli, 2002, p.172, tradução nossa)7 e que, frequentemente, em trabalhos atuais (Pearl, 2007; Pagura, 2010) não está nem ao menos citada como uma categoria, temos evidência de uma lacuna no campo disciplinar dos Estudos da Interpretação. Além do mais, parece ser frequentemente ignorado que a interpretação de línguas de sinais também é interpretação de línguas orais quando a direcionalidade é da língua de sinais para uma língua oral. Logo, não há razão para que a interpretação de línguas de sinais deixe de ser estudada, classificada e divulgada como tal, pois isto vai promover uma maior abrangência e conhecimento que vai qualificar, inclusive, a didática da tradução.

\footnotetext{
${ }^{7}$ No original: [...] the interpretation of sign languages is an integral part of the general study of interpretation and that no description (practical or theoretical) of interpretation which fails to take account of sign language interpretation can be regarded as complete (Ingram, 1978, apud Bidoli, 2002, p.172).
} 
Os Estudos da Tradução, os Estudos da Interpretação e os estudos sobre as línguas de sinais vêm se entrelaçando para constituírem o que se chamou, no Brasil, de Estudos da Tradução e da Interpretação de Línguas de Sinais (ETILS) (Souza, 2010; Rodrigues; Beer, 2015).

É possível visualizar, na figura 1, uma série de acontecimentos que culminaram no surgimento dos ETILS, sem descartar a importante contribuição da criação, a partir de 2008, dos cursos superiores de formação de intérpretes de Libras, que continuam se expandindo, tanto em instituições públicas quanto privadas.

Figura 1 - Linha do tempo da evolução da pesquisa até o primeiro trabalho acadêmico sobre interpretação de línguas de sinais no Brasil

\begin{tabular}{|c|c|c|c|c|}
\hline $\begin{array}{l}\text { Obra } \\
\text { fundadora } \\
\text { dos estudos } \\
\text { sobre as } \\
\text { línguas de } \\
\text { sinais } \\
\text { (STOKOE, } \\
\text { 1960) }\end{array}$ & $\begin{array}{l}\text { Proposição } \\
\text { do campo } \\
\text { disciplinar } \\
\text { dos Estudos } \\
\text { da Tradução } \\
\text { (HOLMES, } \\
\text { 1972) }\end{array}$ & $\begin{array}{l}\text { Texto, } \\
\text { publicado em } \\
\text { português, } \\
\text { que inaugura } \\
\text { a descrição } \\
\text { da Libras } \\
\text { (REHFELDT, } \\
\text { 1983) }\end{array}$ & $\begin{array}{l}\text { Primeiro } \\
\text { texto } \\
\text { propondo os } \\
\text { Estudos da } \\
\text { Interpretação } \\
\text { (SALEVSKY, } \\
\text { 1993) }\end{array}$ & $\begin{array}{l}\text { Primeiro } \\
\text { trabalho, de } \\
\text { pós-graduação } \\
\text { stricto sensu, } \\
\text { sobre a } \\
\text { interpretação } \\
\text { de Libras } \\
\text { (PIRES, 1999) }\end{array}$ \\
\hline
\end{tabular}

Fonte: elaborado pela autora

Outro fator que impulsiona as pesquisas na área é o aumento do número de eventos que incluem os ETILS e, de modo particular, aqueles dedicados especialmente a esta temática, sendo o mais conhecido o Congresso Nacional de Pesquisas em Tradução e Interpretação de Libras e Língua Portuguesa. ${ }^{8}$

A preocupação mais recente é com a didática da tradução e da interpretação, e foi a partir desta inquietação que surgiu o I ENAPTILSP Encontro Nacional de Professores de Tradução e Interpretação de Libras e Língua Portuguesa das Universidades Federais. ${ }^{9}$ Este primeiro encontro, que proporcionou a troca de experiências e elaboração de propostas conjuntas de profissionais de sete universidades (Universidade Federal de

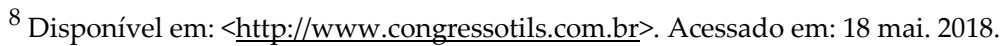

${ }^{9}$ Disponível em: $<$ https://enaptilsp1.faiufscar.com>. Acessado em: 18 mai. 2018.
} 
São Carlos, Universidade Federal de Santa Catarina, Universidade Federal de Goiás, Universidade Federal do Rio Grande do Sul, Universidade Federal do Rio de Janeiro, Universidade Federal de Roraima e Universidade Federal do Espírito Santo), certamente irá aperfeiçoar e sintonizar as instituições participantes em direção a uma maior excelência e, consequentemente, ao reconhecimento por parte do mundo acadêmico.

\subsection{Evidências bibliométricas}

Com o propósito de explicitar as relações entre interpretação de línguas orais e de línguas de sinais, selecionei as publicações, a partir de 2008 (abertura do primeiro curso de bacharelado em Letras/Libras, na Universidade Federal de Santa Catarina), que fazem levantamentos de caráter bibliométrico especificamente sobre a interpretação interlíngue no Brasil, e encontrei somente três textos: uma tese e dois artigos.

A tese de Santos (2013) faz um levantamento e análise de teses e dissertações que abordaram a Libras. Santos, Costa e Galdino (2016), por sua vez, concentram-se em artigos publicados em periódicos especializados em tradução, mas ainda selecionando os textos que enfocam a Libras. Já Cavallo e Reuillard (2016) compilam, em um amplo quadro, as teses, dissertações e artigos sobre os Estudos da Interpretação no Brasil, tal como declarado no título do artigo.

Sistematizando, de forma resumida, os dados destas três publicações, temos:

Quadro 1 - Comparativo de estudos bibliométricos de interpretação de línguas orais (vocais) e de línguas de sinais, entre 1990 e 2015. 


\begin{tabular}{|c|c|c|c|}
\hline $\begin{array}{l}\text { Autoras e } \\
\text { título da obra }\end{array}$ & $\begin{array}{l}\text { Santos,2013: } \\
\text { Tradução/Interpre- } \\
\text { tação de Língua de } \\
\text { Sinais no Brasil: uma } \\
\text { análise das teses e } \\
\text { dissertações de } 1990 \\
\text { a } 2010\end{array}$ & $\begin{array}{l}\text { Santos; Costa; } \\
\text { Galdino, 2016: Nas } \\
\text { Trilhas da Tradução } \\
\text { e Interpretação de } \\
\text { Português-Libras } \\
\text { em Revistas de } \\
\text { Tradução no Brasil }\end{array}$ & $\begin{array}{l}\text { Cavallo; Reuillard, } \\
\text { 2016: Estudos da } \\
\text { Interpretação: } \\
\text { tendências atuais da } \\
\text { pesquisa brasileira }\end{array}$ \\
\hline $\begin{array}{l}\text { Palavras- } \\
\text { chave }\end{array}$ & $\begin{array}{lr}\text { 1. Estudos } & \text { da } \\
\text { Tradução. } & 2 . \\
\text { Tradução } & \mathrm{e} \\
\text { Interpretação } & \text { de } \\
\text { Língua de } & \text { Sinais. } \\
\text { Análise de teses e } \\
\text { dissertações. } \\
\text { Estudos da Tradução } \\
\text { [repetido]. 5. Estado } \\
\text { da arte }\end{array}$ & $\begin{array}{lr}\text { Estudos } & \text { da } \\
\text { Tradução; Estudos } \\
\text { da Tradução e } \\
\text { Interpretação de } \\
\text { Língua de } \\
\text { Produção } \\
\text { acadêmica. }\end{array}$ & $\begin{array}{l}\text { Estudos da } \\
\text { Interpretação. } \\
\text { Tendências Atuais. } \\
\text { Pesquisa Brasileira. }\end{array}$ \\
\hline $\begin{array}{l}\text { Recorte } \\
\text { Espaço } \\
\text { tempo }\end{array}$ & $\begin{array}{l}\text { Teses e dissertações } \\
\text { defendidas sobre a } \\
\text { interpretação de } \\
\text { línguas de sinais, } \\
\text { entre } 1990 \text { e } 2010\end{array}$ & $\begin{array}{lr}\text { Publicações } & \text { sobre } \\
\text { tradução } & \mathrm{e} \\
\text { interpretação de } & \text { de } \\
\text { Português<=>Libras, } \\
1990 \text { a } 2014\end{array}$ & $\begin{array}{l}\text { Teses e dissertações } \\
\text { defendidas sobre a } \\
\text { interpretação de } \\
\text { línguas orais, entre } \\
2006 \text { e } 2015\end{array}$ \\
\hline Corpus & $\begin{array}{l}\text { Banco de Teses e } \\
\text { Dissertações } \\
\text { Capes }\end{array}$ & $\begin{array}{lr}\text { Revista Brasileira de } \\
\text { Tradutores, } \\
\text { Inféis } & \text { Belas } \\
\text { Cadernos } & \text { de } \\
\text { Tradução } & \text { (UFSC), } \\
\text { Traduzires, } & \\
\text { Tradterm } & \text { (USP), } \\
\text { ScientiaTraductionis } \\
\text { (UFSC), r In- } \\
\text { Traduções } & \text { (UFSC) e } \\
\text { Tradução r em } \\
\text { Revista (PUC-Rio) }\end{array}$ & $\begin{array}{lr}\text { Tradução em } & \text { Revista } \\
\text { (PUC-Rio), Belas } & \text { (UnB), } \\
\text { Infiéis r de } & \text { Cadernos } \\
\text { Tradução (UFSC), } & \text { Scientia Traductionis } \\
\text { (UFSC) e } & \\
\text { TradTerm (USP) }\end{array}$ \\
\hline Resu & $\begin{array}{l}26 \text { dissertações } \\
3 \text { teses }\end{array}$ & 36 artigos & $\begin{array}{l}\text { teses, } \\
7 \text { dissertações e } \\
21 \text { artigos }\end{array}$ \\
\hline
\end{tabular}

Fonte: elaborado pela autora 
Tanto na tese de Santos (2013) quanto no artigo de Santos, Costa e Galdino (2016), os próprios títulos e palavras-chave delimitam a pesquisa na tradução/interpretação de língua de sinais e não há indício de que as autoras pretendiam fazer uma investigação que abrangesse os Estudos da Interpretação de forma geral. No artigo de Cavallo e Reuillard (2016), apesar de o título do artigo e das palavras-chave não especificarem que se trata de uma revisão bibliométrica que circunscreve o estudo exclusivamente às línguas orais, existem avisos, no decorrer do texto, de que as autoras somente estão considerando, na perspectiva brasileira dos Estudos da Interpretação, as línguas produzidas por meios vocais:

\footnotetext{
Cada referência à "interpretação" no presente trabalho diz respeito à interpretação entre línguas orais e não à interpretação envolvendo línguas de sinais (Cavallo; Reuillard, 2016, p.353, nota de rodapé)

(...)

Para fins deste estudo, conforme já destacado acima em nota de rodapé, não serão contabilizadas as pesquisas sobre tradução e interpretação envolvendo línguas de sinais (Cavallo; Reuillard, 2016, p.358)
}

O que demonstro é que se levarmos em conta todo o período abrangido por todos estes estudos bibliométricos, de 1990 a 2015, independentemente da modalidade das línguas interpretadas, teríamos o seguinte panorama:

\section{Quadro 2 - Cômputo unificado de produções nos Estudos da Interpretação, no Brasil, de 1990 a 2015}

\begin{tabular}{|c|c|c|c|}
\hline De 1990 a 2015 & Línguas orais & Línguas de sinais & Total \\
\hline Artigos & 21 & 36 & 57 \\
\hline Dissertações & 7 & 26 & 33 \\
\hline Teses & 3 & 3 & 6 \\
\hline
\end{tabular}

Fonte: elaborado pela autora 
Partindo da perspectiva da interpretação das línguas orais, existe um aumento de, aproximadamente, $71 \%$ no número de artigos se forem somados com aqueles sobre línguas de sinais. As dissertações quase quadruplicam, e a quantidade de teses dobra.

É inegável que a produção combinada de todas as variedades de interpretação aumentaria de maneira significativa se considerássemos uma só categoria. Em trabalhos que pretendam representar os Estudos da Interpretação de uma maneira completa e extensiva, é necessária uma abertura para esta nova (e, para alguns pesquisadores, desconhecida) forma de interpretação interlíngue de modo a que os resultados possam refletir em avanços, reconhecimento e valorização de nosso campo disciplinar como um todo.

\section{Apontando para um Futuro Colaborativo}

Por meio desta análise de publicações que fizeram levantamentos sobre investigações na área dos Estudos da Interpretação no Brasil, tive como objetivo evidenciar que a divisão entre línguas orais e línguas de sinais nem sempre é vantajosa para nosso campo disciplinar. Excetuando-se os trabalhos que têm como objeto de estudo, de forma particular, uma ou outra modalidade de língua (oral-auditiva ou gestual-visual), nos casos em que se pretenda demonstrar uma visão geral, é imprescindível incluir todas as formas de interpretação possíveis. A partir do momento em que os investigadores não se sintam seguros para proceder a uma análise de outros tipos de interpretação, as parcerias e estudos colaborativos são a melhor solução, inclusive para o compartilhamento de conhecimentos de diferentes áreas de atuação.

A partir do momento em que mais investigações reconhecerem a interpretação de línguas de sinais como parte integrante dos Estudos da Interpretação, considerando-as como mais uma possibilidade de línguas de trabalho, poderemos unir esforços para mostrar evidências do crescimento e importância de nossa área profissional e acadêmica.

Talvez, devêssemos começar a considerar, para fins de classificação, interpretação interlíngue unimodal/monomodal (línguas orais entre si ou línguas de sinais entre si) e bimodal/intermodal (entre uma língua de sinais 
e uma língua oral) (Nicodemus; Emmorey, 2013). O que é importante ressaltar é que Mikkelson (2009, s/p) já postulava que, apesar das diferentes línguas e variedades de contextos de trabalho e "independentemente do adjetivo que acompanhe a palavra intérprete", o grande diferencial parece ser as condições díspares de trabalho e não a natureza da interpretação em si.

Considerando que as línguas de sinais são línguas legítimas e que a sua interpretação interlíngue também pode ser de e para uma língua oral (direcionalidade partindo da língua de sinais para a voz, em língua vocal) não há por que considerá-la como uma categoria à parte das línguas orais, pois todas integram os Estudos da Interpretação.

A meu ver, o que deveria acontecer é a soma das forças de qualquer tipo de interpretação interlíngue, seja de quais línguas forem - línguas orais, línguas de sinais, línguas indígenas, línguas de imigração, línguas de fronteira etc. - para a criação de mais linhas de pesquisa nas pósgraduações e, consequentemente, de investigações, que pertencessem aos Estudos da Tradução e, dentro destes, os Estudos da Interpretação. Assim, poderemos unir nossa produção e esforços para que haja, realmente, "sinais positivos para o futuro acadêmico e para a consolidação da identidade profissional do intérprete" (Cavallo; Reuillard, 2016, p.366), independentemente de quais modalidades de língua sejam trabalhadas.

\section{Referências}

BIDOLI, Cynthia Jane Kellett. Spoken-language and Signed-language interpretation: Are they really so different? In: GARZONE, Giuliana; VIEZZI, Maurizzio (orgs.). Interpreting in the 21st Century: Challenges and opportunities. Selected papers from the 1st Forlì Conference on Interpreting Studies, 9-11 November 2000. Amsterdã: John Benjamins Publishing Company, 2002, p. 171-180.

BRUNSON, Jeremy. Sign Language Interpreting: Moving Towards Professionalization. Embodied Workers Conference, Syracuse, NY, 2004.

CARLIEZ, Maria Luizete Sampaio Sobral; FUSELLIER, Ivani. Collecte des langues des signes des sourds de Soure (Île de Marajó): un parcours 
méthodologique (2008/2013), les enjeux sociaux et politiques de la non reconnaissance des langues des signes émergentes pratiquées par ces sourds. Revista Moara 45, 2016, p. 144-160.

CARNEIRO, Teresa Dias. Intérpretes de línguas orais e intérpretes de Libras: semelhanças e diferenças na formação, atuação e status social. Tradução em Revista, 23, 2017.2, p. 2-19.

CAVALLO, Patrizia; REUILLARD, Patrícia C. R. Estudos da Interpretação: tendências atuais da pesquisa brasileira. Letras \& Letras | Uberlândia | vol. 32/1 I jan/jun 2016.

DE VOS, Connie; ZESHAN, Ulrike. Introduction: Demographic, sociocultural, and linguistic variation across rural signing communities.In ZESHAN, Ulrike; de VOS, Connie (Eds.). Sign Languages in Village Communities. Anthropological and Linguistic Insights. Berlin, Boston: De Gruyter Mouton, 2012, p. 2-26.

EVERSON, Michael. Implementing the ISO 639-2 code for Sign Languages. 2000. Disponível em:

$<$ http://www.signwriting.org/archive/docs1/sw0033-Sign-Language-

Codes.pdf >. Acesso em 10 fev. 2018.

FERREIRA, Lucinda. Por Uma Gramática de Língua de Sinais. 2. ed. Rio de Janeiro: Tempo Brasileiro, 2010.

FIGUEIRA, Mariana Pereira Castro. Comunidade Surda da Fronteira, Experiência "Compartida". Dissertação (Mestrado em Educação Especial). Programa de Pós-Graduação em Educação Especial, Universidade Federal de Santa Maria, 2016.

GIROLETTI, Marisa Fátima Padilha. Cultura Surda e Educação Escolar Kaingang. Dissertação (Mestrado em Educação) - Centro de Ciências da Educação, Universidade Federal de Santa Catarina, Florianópolis, 2008. HOEMANN, Harry; OATES, Eugênio; HOEMANN, Shirley (Eds.). The Sign language of Brazil. Mill Neck, N.Y. : Mill Neck Foundation, 1981. (Orgs.). Linguagem de Sinais do Brasil. Tradução de Mário L. Rehfeldt, Beatriz Macedo, Pe. Vicente Burnier e Guaraci Angelini. Porto Alegre: Pallotti, 1983.

HOLMES, James S. The Name and Nature of Translation Studies. An expanded version of a paper presented in the Translation Section of the Third 
International Congress of Applied Linguistics, Copenhagen, 21-26 August 1972.

INGRAM, R. M. Sign language interpretation and general theories. In: GERVER, D.;

IVARS, Amparo Jiménez. La Traducción a la Vista. Un Análisis Descriptivo. Tese (Doutorado em Tradução e Comunicação). Facultat de Ciències Humanes i Socials. Universitat Jaume I, 1999.

KAKUMASU, James Y. Urubú Sign Language. International Journal of American Linguistics, N.4, vol XXXIV, 1968, p. 275-281.

Urubu-Kaapor. Handbook of Amazonian languages, vol. 1, Desmond C. Derbyshire and Geoffrey K. Pullum (eds.), 1986, p. 326-403.

LOURENÇO, Sílvia Estrela. Guia-Intérprete para pessoa com surdocegueira: Reflexão sobre as tendências e perspectivas de sua formação. In: ALBRES, Neiva de. Aquino Albres; SANTIAGO, Vânia de Aquino Albres (Orgs.). Libras em estudo: tradução/interpretação. São Paulo: FENEIS, 2012, p.109-139.

MARTINOD, Emmanuella. Les LS pratiquées par des sourds isolés de Marajó. (MA thesis, Université Vincennes Saint Denis, Paris 8), 2013.

MCCLEARY; Leland; VIOTTI, Evani. Língua e gesto em línguas sinalizadas. Veredas on Line. Atemática, n.1, p. 289-304 - PPG Linguística/UFJF - JUIZ DE FORA. 2011.

MEIR, Irit; SANDLER, Wendy; PADDEN, Carol; ARONOFF, Mark. Emerging Sign Languages. In: M. Marschark, and P. Spencer (Eds.). Oxford Handbook of Deaf Studies, Language, and Education. Vol. 2. Oxford: Oxford University Press, 2010, p. 267-280.

MIKKELSON, Holly. - Interpreting is interpreting - or is it? -. AIIC.net.

Disponível em: <http://aiic.net/p/3356>. Acesso em: 12 dez. 2017.

MINISTÉRIO DO TRABALHO E EMPREGO (MTE), Brasil. Classificação

Brasileira de Ocupações: CBO. V.3, 196 p. Brasília : MTE, SPPE, 2010.

Disponível em:

$<$ http://www.mtecbo.gov.br/cbosite/pages/download?tipoDownload=3>.

Acesso em: 10 dez. 2018. 
MONFORT, Aude-Valérie. "AIIC's first sign-language member: Maya de Wit". AIIC.net. March 31, 2014. Disponível em: <http://aiic.net/p/6866>. Acesso em 30 dez., 2017.

NICODEMUS, Brenda; EMMOREY, Karen. Direction asymmetries in spoken and signed language interpreting. Bilingualism: Language and Cognition, Volume 16, Issue 03, July 2013, p. 624-636.

PAGURA, Reynaldo José. A Interpretação de conferências no Brasil: história de sua prática profissional e a formação de intérpretes brasileiros. Tese (Doutorado em Letras). Universidade de São Paulo, 2010. PEARL, Stephen. Scripta manent, verba volant. Written translation and simultaneous interpretation - siblings or distant cousins. An exploration of some less apparent differences. TRANS - Revista de Traductología. N. II, 215-230. Universidad de Málaga: Departamento de Traducción e Interpretación, 2007.

PEREIRA, Éverton Luís. "Fazendo cena na cidade dos mudos": surdez, práticas sociais e uso da língua em uma localidade no sertão do Piauí. Tese (Doutorado em Antropologia Social) Programa de Pós-Graduação em Antropologia Social. Universidade Federal de Santa Catarina, 2013. PETRONIO, Karen. Deaf-Blind Interpreting: Building on what you Already Know. Cadernos de Tradução. QUADROS, Ronice Müller de. Tradução e Interpretação de Línguas de Sinais. v. 2, n. 26, 2010, p.237-273.

PIRES, Cleidi Lovatto. Questões de fidelidade na interpretação em Língua de Sinais. Dissertação (Mestrado em Educação). Universidade Federal de Santa Maria, 1999.

QUADROS, Ronice Müller de; KARNOPP, Lodenir Becker. Língua de sinais brasileira. Estudos Linguísticos. Porto Alegre: Artmed, 2004.

REHFELDT, Gládis K. Fundamentos Linguísticos para a Descrição da Linguagem de Sinais do Brasil. In: HOEMANN, Harry; OATES, Eugênio; HOEMANN, Shirley (Orgs.). Linguagem de Sinais do Brasil. Tradução de Mário L. Rehfeldt, Beatriz Macedo, Pe. Vicente Burnier e Guaraci Angelini. Porto Alegre: Pallotti, 1983, p.25-40.

RODRIGUES, Carlos Henrique; BEER, Hanna. Os estudos da tradução e da interpretação de línguas de sinais: novo campo disciplinar emergente? 
Cadernos de Tradução. Florianópolis, v. 35, n. 2, p. 17-45, out. 2015. Disponível em:

$<$ https://periodicos.ufsc.br/index.php/traducao/article/view/21757968.2015v35nesp2p17>. Acesso em: 11 dez. 2017.

SALEVSKY, Heidemarie. The Distinctive Nature of Interpreting Studies. In: Target 5/2, 1993, p. 149-167.

SANTOS, Silvana Aguiar dos. Tradução/interpretação de língua de sinais no Brasil: uma análise das teses e dissertações de 1990 a 2010. Tese (Doutorado em Estudos da Tradução) - Centro de Comunicação e Expressão, Universidade Federal de Santa Catarina, Florianópolis, 2013. Disponível em: <http://www.bu.ufsc.br/teses/PGET0178-T.pdf>. Acesso em: 11 nov. 2017.

; COSTA, Mairla Pereira Pires; GALDINO, Thuanny Sá. Nas Trilhas da Tradução e Interpretação de Português-Libras em Revistas de Tradução no Brasil. Cadernos de Letras da UFF. Dossiê: A crise da leitura e a formação do leitor $\mathrm{n}^{\mathrm{o}}$ 52, p. 525-545. 2016.

SAVULAHTI, Ari. Interpreting With Immigrant Deaf People, A Qualitative Case Study of an Interpreted Event. Degree Programme in Sign Language Interpreting (EUMASLI) (Master's Degree), unpublished MA thesis, EuMaSLI, Kuopio, Humak University of Applied Sciences (Finland), 2012. Disponível em:

$<$ https://www.theseus.fi/bitstream/handle/10024/45606/Savulahti_Ari.pdf?s equence $=1 \&$ isAllowed $=y>$. Acesso em: $12 \mathrm{dez} .2017$.

SOUZA, Saulo Xavier de. Performances de tradução para a Língua Brasileira de Sinais observadas no curso de Letras-Libras. Dissertação (Mestrado em Estudos da Tradução). Universidade Federal de Santa Catarina, Centro de Comunicação e Expressão, Florianópolis, 2010.

SUMAIO, Priscilla Alyne. Sinalizando com os Terena: um estudo do uso da LIBRAS e de sinais nativos por indígenas surdos. 2014. $123 \mathrm{f}$. Dissertação (Mestrado em Linguística e Língua Portuguesa). Faculdade de Ciências e Letras, Universidade Estadual Paulista Júlio de Mesquita Filho, 2014. 


\section{Resumo}

A interpretação de línguas de sinais tem sido frequentemente desconsiderada até mesmo em trabalhos específicos dos Estudos da Interpretação. Sistematizo as mais recentes publicações, de caráter bibliométrico, que mapeiam teses, dissertações e artigos sobre a interpretação de línguas orais e de línguas de sinais, ponderando as consequências deste dualismo, mutuamente excludente, para nosso campo disciplinar. Diante dos resultados, proponho uma abordagem integradora que respeite as especificidades de estudo de cada tipo de interpretação, mas que promova o conhecimento geral das diversas classificações, principalmente pelos formadores em âmbito acadêmico.

Palavras-chave: Estudos da Tradução; Estudos da Interpretação; línguas de sinais.

\section{Abstract}

Sign language interpreting has been often disregarded even in specific Interpreting Studies papers. Systematizing the most recent bibliometric publications that map theses, dissertations and articles on spoken (vocal) language and sign language interpreting, it is possible to foresee the consequences of this mutually exclusive dualism for our disciplinary field. Based on the results, an integrative approach is proposed that respects the specificities of each type of interpreting, but that promotes the general knowledge of the different interpreting classifications, mainly by institutions, trainers and scholars, in different academic scopes.

Keywords: Translation studies; interpreting studies; sign languages. 